\title{
Cost-Effectiveness of Three Alternative Boosted Protease Inhibitor-Based Second-Line Regimens in HIV-Infected Patients in West and Central Africa
}

\author{
S. Boyer ${ }^{1}$ - M. L. Nishimwe (D) - L. Sagaon-Teyssier ${ }^{1,2} \cdot$ L. March $^{3} \cdot$ S. Koulla-Shiro ${ }^{4} \cdot$ M.-Q. Bousmah ${ }^{1,2} \cdot$ R. Toby ${ }^{5}$.

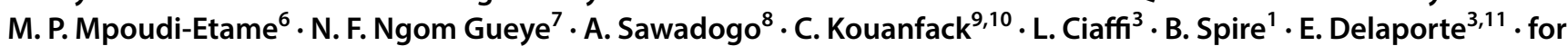 \\ the 2-Lady Group
}

Published online: 4 July 2019

(c) The Author(s) 2019

\begin{abstract}
Background While dolutegravir has been added by WHO as a preferred second-line option for the treatment of HIV infection, boosted protease inhibitor (bPI)-based regimens are still needed as alternative second-line options. Identifying optimal bPI-based second-line combinations is essential, given associated high costs and funding constraints in low- and middleincome countries. We assessed the cost-effectiveness of three alternative bPI-based second-line regimens in Burkina Faso, Cameroon and Senegal.

Methods We used data collected over 2010-2015 in the 2LADY trial/post-trial cohort. Patients with first-line antiretroviral therapy (ART) failure were randomly assigned to tenofovir/emtricitabine + lopinavir/ritonavir (TDF/FTC LPV/r; arm A), abacavir + didanosine + lopinavir/ritonavir (arm B), or tenofovir/emtricitabine + darunavir/ritonavir (arm C). Costs (US dollars, 2016), quality-adjusted life-years (QALYs) and incremental cost-effectiveness ratios were computed for each country over 24 months of follow-up and extrapolated to 5 years using a simulated patient-level Markov model. We assessed uncertainty using cost-effectiveness acceptability curves, scenarios and prices threshold analysis.

Results In each country, over 24 months, arm A was significantly less costly than arms B and C (incremental costs ranging from US\$410-\$US721 and US\$468-US\$546 for B and C vs A, respectively) and offered similar health benefits (incremental QALY: -0.138 to 0.023 and -0.179 to 0.028 , respectively). Over 5 years, arm A remained the least costly, health benefits not being significantly different between arms. Compared with arms B and C, in each study country, Arm A had a $\geq 95 \%$ probability of being cost-effective for a large range of cost-effectiveness thresholds, irrespective of the scenario considered. Conclusions Using TDF/FTC LPV/r as a bPI-based second-line regimen provided the best economic value in the three study countries.
\end{abstract}

Trial Registration ClinicalTrials.gov Identifier: NCT00928187.

S. Boyer and M. L. Nishimwe contributed equally.

Members of the ANRS 12169 2LADY Study Group are listed in "Acknowledgements".

Electronic supplementary material The online version of this article (https://doi.org/10.1007/s41669-019-0157-9) contains supplementary material, which is available to authorized users.

M. L. Nishimwe

marie.nishimwe@inserm.fr

Extended author information available on the last page of the article 


\section{Key Points for Decision Makers}

The second-line regimen tenofovir/emtricitabine + lopinavir/ritonavir (TDF/FTC LPV/r) saved costs and had similar health benefits to abacavir + didanosine + lopinavir/ritonavir (ABC ddI LPV/r) and tenofovir/emtricitabine + darunavir/ritonavir (TDF/FTC DRV/r) in HIVpositive patients with first-line ART failure in Burkina Faso, Cameroon and Senegal.

Cost savings were driven by the lower monthly prices of the two nucleoside reverse transcriptase inhibitor (NRTI) drugs (TDF/FTC vs ABC ddI) and the boosted protease inhibitor (LPV/r vs DRV/r), even when the most recent antiretroviral drug prices (reported for the year 2018) were taken into consideration.

Using TDF/FTC LPV/r as alternative boosted protease inhibitor-based second-line therapy to dolutegravir, which was added as a WHO preferred second-line option in July 2018, may be the most efficient use of resources in low- and middle-income countries.

\section{Introduction}

At the end of 2017, the number of people living with HIV (PLHIV) accessing antiretroviral therapy (ART) reached 21.7 million people worldwide, with 13.5 million in SubSaharan Africa [1]. Second-line ART only concerned a minority of patients, estimated at approximately $5.3 \%$ of all patients on ART in low- and middle-income countries (LMIC) in 2014 [2]. However, the need for second-line ART is forecast to grow in the coming years because of high firstline treatment failure rates, estimated at between 8 and 23\% after 5 years [3]. This trend is expected to be reinforced by the growing demand for first-line ART following recent international guidelines recommending ART initiation irrespective of CD4 count [4]. Furthermore, PLHIV in LMIC with first-line ART failure generally show accumulation of drug resistance due to late diagnosis of treatment failure in the absence of HIV RNA monitoring [5]. Given that the risk of first-line treatment failure increases over time-with the possible associated emergence of a variety of resistance patterns-how best to provide second-line therapy is a crucial issue in LMIC [6].

The World Health Organization's (WHO) 2016 guidelines suggested using second-line regimens based on boosted protease inhibitors (bPI) with two nucleoside reverse transcriptase inhibitors (NRTIs) after the failure of non-nucleoside reverse transcriptase inhibitor (NNRTI)based first-line regimens [4]. The preferred WHO options for adults were ritonavir-boosted lopinavir (LPV/r) or atazanavir (ATV/r). Alternative options for bPI included ritonavir-boosted darunavir (DRV/r). The WHO's updated 2018 guidelines added a recent integrase inhibitor, dolutegravir (DTG), in combination with a two-NRTI backbone among the preferred second-line options [7].

The recent clinical trial ANRS 12169 2LADY, conducted in Burkina Faso, Cameroon and Senegal, provided evidence for the short-term efficacy and safety of the following three bPI-based second-line regimens: (1) tenofovir/emtricitabine + lopinavir/ritonavir (TDF/FTC LPV/r), (2) tenofovir/emtricitabine + darunavir/ritonavir (TDF/ FTC DRV/r) - both recommended in WHO 2016 and 2018 guidelines-and (3) abacavir + didanosine + lopinavir/ritonavir (ABC ddI LPV/r), which was recommended until 2010 but had never been evaluated [8]. Clinical outcomes assessed at 1 year showed that all three obtained similar and satisfactory virologic control as well as good immune recovery, safety and tolerance.

Beyond the clinical challenges, the choice of the second-line combinations to use in LMIC raises important economic questions. The yearly cost of bPI-based secondline ART is, on average, twice that of first-line ART [9]. Moreover, the growing number of PLHIV requiring more expensive second-line ART, together with the increased demand for first-line as a consequence of the international guidelines highlighted above, is stretching already strained budgets [10]. Despite these challenges, literature on the economic value of second-line ART in LMIC is scarce. Several studies have evaluated the cost-effectiveness of switching to second-line after first-line failure [11-13], but we identified only one which assessed alternative secondline combinations [14]. In this study, the authors compared a simplified second-line therapy based on lopinavir/ritonavir + raltegravir with lopinavir/ritonavir + 2NRTI in South Africa and Nigeria. Furthermore, no economic evaluation of the alternative bPI-based second-line regimens recommended by the WHO has yet been published.

Identifying the optimal bPI-based second-line combinations to use in LMIC, by jointly assessing their respective benefits and costs, is essential to optimize available resources, especially given the sometimes small differences in health benefits provided by antiretroviral drugs (ARV) whose costs vary significantly. This study compared, over the short and medium terms, the health benefits, costs and cost-effectiveness of three alternative bPIbased second-line regimens assessed within the ANRS 12169 2LADY trial in three LMIC: Burkina Faso, Cameroon and Senegal. 


\section{Methods}

\subsection{Data and Study Population}

We used data collected over the 2010-2015 period in the randomized, 48-week (48 W) 2LADY trial and subsequent post-trial follow-up. Full details of the trial design, analysis and results are described elsewhere [8].

Briefly, the trial was conducted between January 2010 and September 2013 in four Day-Care Centres for HIV infection located in the national reference hospitals of Burkina Faso, Cameroon and Senegal. It enrolled 454 HIV-1 positive adults (aged $>18$ years) with NNRTIbased first-line ART failure after a minimum 6 months of treatment and without recent (3 months) ART switching. Participants were randomly assigned (1:1:1) to tenofovir/emtricitabine + lopinavir/ritonavir (arm A); abacavir + didanosine + lopinavir/ritonavir (arm B); or tenofovir/emtricitabine + darunavir/ritonavir (arm C). Clinical evaluation and laboratory monitoring (including renal and liver function tests, total blood count and plasma viral load) were performed at 4 weeks, then every 3 months during the first year and every 6 months thereafter. At the end of the trial (i.e. $48 \mathrm{~W}$ visit of the last patient enrolled), participant follow-up was continued in a cohort study using the same procedures until December 2015 (date of the last visit).

The base-case analysis was conducted using a modified intention-to-treat analysis (mITT), which included 451 participants (i.e. 152, 145 and 154 in arms A, B and $\mathrm{C}$, respectively) who received at least one dose of the assigned treatment. Three participants with major protocol violations were excluded. Overall, median (interquartile range [IQR]) age of participants was $38[32 ; 46]$ years and $72 \%$ were women. Ninety participants were followed in Burkina Faso, 302 in Cameroon and 59 in Senegal. At baseline, median [IQR] of CD4 cells $/ \mathrm{mm}^{3}$ and viral load (VL) $\left(\log _{10}\right)$ was $183[87 ; 290]$ and 4.5 [4.0; 5.1], respectively, and $27 \%$ of patients had a VL $\geq 100,000$ copies $/ \mathrm{mL}$. The longest follow-up duration was 60 months $(n=15)$ and median [IQR] follow-up was 3.0 [2.5; 4.0] years.

\subsection{Outcomes}

The main outcomes considered in the cost-effectiveness analysis included costs, quality-adjusted life-years (QALYs) and incremental cost-effectiveness ratios (ICERs). Outcomes were first computed over the first 24 months $(24 \mathrm{M})$ of follow-up based on both the trial data and its subsequent cohort and then extrapolated to 5 years using a simulated patient-level Markov model.
Health benefits and costs were estimated overall (i.e. for the whole study population in the three study countries) and for each country. Beyond the first year, they were discounted at an annual rate of $3.5 \%$ [15].

\subsubsection{Health Benefits and Cost Measurement over $24 \mathrm{M}$ of Follow-Up}

2.2.1.1 Health Benefits In the base-case analysis, for each country and for each arm we assessed the mean number of QALYs per patient with their respective $95 \%$ confidence intervals (CI) over $24 \mathrm{M}$ of follow-up. QALYs were computed as the time spent in a specific health state (defined according to CD4 count ranges as described in Sect. 2.2.2.1) weighted by the utility score corresponding to that health state. Utility estimates associated with CD4 count range were obtained from the DART trial in Uganda using the time trade-off method (Table 1) [16]. For each country and for each arm, we also assessed life-years saved (LYS) using the Kaplan-Meier (KM) estimator. Data were censored at the $24 \mathrm{M}$ visit or, if follow-up was shorter, at the time of the last visit. In addition, we assessed the following outcomes at the same timepoint: virological success (proportions of patients with $\mathrm{VL}<50$ copies $/ \mathrm{mL}$ and $<1000$ copies $/ \mathrm{mL}$ ), increase in CD4 cell count and proportion of patients who switched to third-line therapy.

2.2.1.2 Costs Costs were measured from enrolment to the $24 \mathrm{M}$ visit or, if follow-up was shorter, to the last visit. Censoring costs were not accounted for as the attrition rate over the first $24 \mathrm{M}$ was low (17/451, i.e. 3.3\%) [17]. Costs were assessed from the health system perspective and included the following cost items: ARV, concomitant drugs, laboratory tests, outpatient consultations and inpatient stays. Total costs were estimated for each arm, overall and by country, as the sum of all individual healthcare resources used by participants multiplied by their corresponding unit cost in the study country. Data on healthcare resources consumed by participants over the study period (2010-2015) were obtained through standardized case report forms. Their respective unit costs were obtained for the years 2015 and

Table 1 Utility weights used in the model

\begin{tabular}{|c|c|c|}
\hline $\mathrm{CD} 4$ count range & WHO stage match & Utility weights \\
\hline HS4 $\left(>500\right.$ cells $\left./ \mathrm{mm}^{3}\right)$ & Symptomatic HIV & 0.75 \\
\hline $\begin{array}{l}\text { HS3 (350-500 cells/ } \\
\left.\mathrm{mm}^{3}\right)\end{array}$ & Symptomatic HIV & 0.75 \\
\hline $\begin{array}{l}\text { HS2 (200-349 cells/ } \\
\left.\mathrm{mm}^{3}\right)\end{array}$ & $\begin{array}{l}\text { Minor AIDS-defining } \\
\text { illness }\end{array}$ & 0.49 \\
\hline HS1 $\left(<200\right.$ cells $\left./ \mathrm{mm}^{3}\right)$ & $\begin{array}{l}\text { Mean of minor and major } \\
\text { AIDS-defining illness }\end{array}$ & 0.35 \\
\hline
\end{tabular}

HS Health State, WHO World Health Organization 
2016 in each study site using trial accounting information and data collection, except for ARV costs, which were valued using the WHO Global Price Reporting Mechanism database [Supplemental Table 1, see Electronic Supplementary Material (ESM)] [18]. In the base-case analysis, the range of yearly prices of ARV according to the study country was as follows: US\$283-313 for TDF/FTC LPV/r, US\$474-701 for ABC ddI LPV/r and US\$544-629 for TDF/ FTC DRV/r. For each resource category and for each arm, we calculated the mean healthcare use and the mean cost per patient-year. Costs in Franc de la Communauté Financière Africaine (FCFA) were first converted to US dollars using the year-specific exchange rates. These nominal costs were then deflated in real value expressed in 2016 US dollars [19]. Data on exchange rates and inflation were obtained from the World Bank [20].

\subsubsection{Extrapolation of Health Benefits and Costs over 5 Years}

2.2.2.1 Model Description As HIV infection is a chronic disease, a simulated patient-level Markov model was also developed based on trial and post-trial data to assess participants' disease progression and outcomes over the medium term (i.e. 5 years) [21, 22]. The structure of the model used to capture the treatment-modified disease progression of participants switching to bPI-based second-line ART regimens is depicted in Supplemental Fig. 1 (see ESM). The model has four transitional health states defined according to CD4 count ranges $\left[<200\right.$ cells $/ \mathrm{mm}^{3}$ (health state 1, HS1); 200-350 cells $/ \mathrm{mm}^{3}$ (HS2); 350-500 cells $/ \mathrm{mm}^{3}$ (HS3); $\geq 500$ cells $/ \mathrm{mm}^{3}$ (HS4)], and one absorbing health state corresponding to death, whether related or not to HIV infection (HS5). This structure is a simplification of a previous model used in high-income countries that included VL levels in the definition of health states [23] and that has been applied to HIV-positive patients in LMIC [12, 24].

At enrolment, patients were categorized into one of the first four health states (55.4\% were in HS1, 28.4\% in HS2, $12.9 \%$ in HS3 and 3.3\% in HS4). Depending on the disease progression, they either remained in the same health state or moved to another health state (including death). Exact dates of death and CD4 count measurements observed in the study population were specified in the Markov model to define transitions between health states. To fit data availability (quarterly follow-up during the first year and biannually thereafter), cycle durations were set up to 3 months for the first year of follow-up and 6 months after week 48 . Transition probabilities between health states were estimated from the intensity transition matrix, which indicated the rate at which patients moved from state $r$ to state $s$ in the period $t$ to $t+u[21,22]$. The intensity transition matrix was computed using transitions between states that were observed in the study population during 20 trimesters of follow-up (corresponding to 4 trimesters in the first year and 8 semesters after week 48). Effects of participants' individual characteristics on transition probabilities between health states were also taken into account in the model using an exponential specification under the proportional hazards [22]. The final model was selected using the forward stepwise method and included the following covariates: gender, CD4 cells $/ \mathrm{mm}^{3}$ at ART initiation, treatment arm and country of residence (all fixed), having experienced virological failure after switching to second-line ART and age (both time varying) (see Appendix 2 in the ESM).

2.2.2.2 Health Benefits Using the Markov model estimates (i.e. transition probabilities adjusted for individual characteristics), we predicted health states after $24 \mathrm{M}$ and until 5 years (i.e. 12 cycles of 3 months) for participants not observed over that period in each study country. To guarantee stable results, we ran 15,000 replications per patient. Life tables were used to update probability matrices to account for the probability of death conditional on country, age and gender. The arm-specific number of QALYs was estimated at each simulated cycle by multiplying the number of patients by the time spent in the different health states (except death) weighted by the utility score corresponding to each health state. The total number of QALYs per arm and per country at 5 years was then computed by adding the cumulated number of QALYs over the 12 simulated cycles and the number of QALYs accrued over the first $24 \mathrm{M}$ of follow-up.

2.2.2.3 Costs The previous simulations of participants' health states from $24 \mathrm{M}$ to 5 years were used to estimate costs beyond $24 \mathrm{M}$. For each arm and each country, a mean cost per 3-month cycle was assigned to each health state (see Appendix 3 in the ESM). The arm- and country-specific costs were also estimated first at each simulated cycle by multiplying the number of patients in a given health state by the corresponding health state mean cost and second, over 3 years as the total (cumulative) costs accrued over the 12 cycles. Costs estimations obtained previously over the first $24 \mathrm{M}$ were then added to this estimation to compute the total cost per arm and per country at 5 years.

\subsection{Economic and Sensitivity Analysis}

Methods employed in the economic analysis are in line with those recommended in international guidelines and, in particular, follow standards for economic evaluation in clinical trials $[15,17]$. In each study country, ICERs were computed for each strategy, compared with the next most costly, non-dominated strategy, as the differential mean costs divided by the differential health benefits [25]. As 
suggested by WHO [26], we considered an intervention to be very cost-effective if its ICER was lower than one times the per-capita gross domestic product (GDP) (i.e. US\$584 in Burkina Faso, US\$1392 in Cameroon and US\$1231 in Senegal, corresponding to the yearly 2016 per-capita GDP at nominal values [27]). As this approach may be criticized because of the uncertainty of the value of $\lambda$ corresponding to the maximum cost-effectiveness threshold [28], we varied $\lambda$ from US\$0 to US $\$ 10,000$ in each study country.

Uncertainty surrounding the estimation of the cost-effectiveness outcomes was addressed using the cost-effectiveness acceptability curve (CEAC) methods [29]. Employing a non-parametric technique based on bootstrapping, we simulated 50,000 pairs of incremental costs and QALYs and represented them in the cost-effectiveness plan (CEP). Based on the simulations, we calculated the $95 \% \mathrm{CI}$ for both incremental costs and QALYs as well as the probability of TDF/ FTC LPV/r being cost-effective compared with both other arms at different thresholds (i.e. the proportion of the incremental cost-effect pairs that fall below the cost-effectiveness threshold represented in the CEP by the line with slope $\lambda$ drawn through the origin).

In addition, we conducted a deterministic one-way sensitivity analysis both for the base-case analysis conducted over $24 \mathrm{M}$ and for the extrapolation of the results to 5 years. First, we considered the most recent information on ARV prices reported for LMIC by Médecins Sans Frontières (MSF) for the year 2018 (Scenario 1) [30]. We also examined the effect on the ICERs when considering (1) LYS to measure health benefits (Scenario 2) and (2) an alternative source for utility estimates to compute QALYs (Scenario 3) [31]. We then varied the discount rate from 0 to $6 \%$ (Scenario $4 a$ and $4 b$ ).

Finally, for each study country, we calculated the price thresholds that made DRV/r-based regimens as cost-effective as arm A (i.e. to be cost-effective with a probability of 50\% for a cost-effectiveness threshold of one times the country's per-capita GDP). Price thresholds were not computed for the comparison with arm B considering results of the clinical trial, which argue for the elimination of this combination from WHO recommendations [8].

Analyses were performed using SAS version 9.4 and $R$ version 3.5.0 (packages msm and markovchain).

\section{Results}

\subsection{Base-Case Analysis}

At $24 \mathrm{M}, 12$ participants had died $(3,4$ and 5 in arm A, B and $\mathrm{C}$, respectively, $p=0.82), 17$ were lost to follow-up $(9$, 4 and 4 in arms A, B and C, respectively, $p=0.26$ ), and 422 were still in care including 84 in Burkina Faso, 285 in Cameroon and 52 in Senegal. In each country, health benefits were very similar between the three arms. Discounted mean $(95 \%$ CI) QALYs over $24 \mathrm{M}$ ranged from 1.037 to $1.201 \mathrm{in}$ arm A, 1.060-1.119 in arm B and 0.964-1.126 in arm C according to country. In addition, the mean increase (95\% CI) in CD4 cell count from baseline to $24 \mathrm{M}$ was 208 (131-308) cells/ $\mathrm{mm}^{3}$ without significant differences between arms (either overall, or according to country) (Table 2). In all three study countries, the proportion of virological success was also not significantly different in the three arms, irrespective of VL threshold.

Table 3 describes healthcare use and corresponding mean costs per patient-year estimated over $24 \mathrm{M}$, overall (i.e. for the whole study population) and per study country. Total mean costs (SD) per patient-year were US\$686.9 (112.0), US\$1011.9 (502.8) and US\$955.7 (209.5) in arms A, B and $\mathrm{C}$, respectively. Overall, total mean costs per patient-year ranged from US\$567 to US\$762 in arm A, US\$834-1098 in arm B and US\$805-1140 in arm C according to country. In all three arms for all three countries, the main cost item was ARV, representing 36-49\% of total costs in arm A, 55-62\% in arm B and 51-65\% in arm C. All cost items were broadly similar across arms except ARV.

In the three study countries, arm A was significantly less costly than the other two arms and offered similar health benefits (Table 4). Indeed, mean cost (95\% CI) differences were estimated at US\$410 (280-505) in Burkina Faso, US\$532 (441-621) in Cameroon and US\$721 (626-819) in Senegal for B vs A, and US\$488 (439-532), US\$468 (395-538) and US\$546 (283-764), respectively, for C vs A. Health benefits were not significantly different between the three arms with mean $(95 \% \mathrm{CI})$ incremental QALYs of -0.021 ( -0.140 to 0.169) in Burkina Faso, $0.023(-0.060$ to 0.106$)$ in Cameroon and $-0.138(-0.319$ to 0.049$)$ in Senegal for arm B vs A, and $0.028(-0.107$ to 0.162$)$, -0.073 ( -0.153 to 0.008$)$ and $-0179(-0.381$ to 0.018$)$, respectively, for $\mathrm{C}$ vs $\mathrm{A}$.

Arm A had a 100\% probability of being cost-effective for both comparisons in the three study countries. Figure 1 represents the CEAC for arm A (compared with B and C, respectively) for each study country. The corresponding cost-effects pairs are presented in Supplemental Fig. 2 (see ESM). The CEAC showed that in the three study countries, the probability of arm A being cost-effective was $\geq 95 \%$ for a large range of cost-effectiveness thresholds (i.e. US\$0-3063 in Burkina Faso, US\$0-5938 in Cameroon and US $\$ 0-10,000$ in Senegal compared with arm B; US\$0-3559 in Burkina Faso and US\$0-10,000 in Cameroon and Senegal compared with arm C).

\subsection{Simulated Patient-Level Markov Model}

Estimated transition probabilities used to predict patients' health states at 5 years, and the effect of individual 
Table 2 Clinical outcomes at 24 months of follow-up (ANRS 12169 2LADY, $n=451$ )

\begin{tabular}{|c|c|c|c|c|c|}
\hline & $\begin{array}{l}\text { TDF/FTC LPV/r } \\
(\operatorname{arm~A,~} n=152)\end{array}$ & $\begin{array}{l}\mathrm{ABC} \text { ddI LPV/r } \\
(\operatorname{arm~B}, n=145)\end{array}$ & $\begin{array}{l}\text { TDF/FTC DRV/r } \\
(\operatorname{arm~C}, n=154)\end{array}$ & Total $(n=451)$ & $p$ value $^{\mathrm{a}}$ \\
\hline Death, $n(\%)$ & $3(2.0)$ & $4(2.8)$ & $5(3.3)$ & $12(2.7)$ & 0.82 \\
\hline Lost to follow-up, $n(\%)$ & $9(5.9)$ & $4(2.8)$ & $4(2.6)$ & $17(3.3)$ & 0.26 \\
\hline In care, $n(\%)$ & $140(92.1)$ & $137(94.5)$ & $145(94.2)$ & $422(93.6)$ & 0.68 \\
\hline Switched to third-line ART, $n(\%)$ & $1(0.7)$ & $3(2.1)$ & $3(2.0)$ & $7(1.6)$ & 0.64 \\
\hline \multicolumn{6}{|c|}{ Immunological and virological outcomes among patients in care at 24 months $(n=421)^{*}$} \\
\hline $\begin{array}{l}\text { Mean increase }(95 \% \mathrm{CI}) \text { in CD4 count } \\
\text { from baseline }\end{array}$ & $214(122-307)$ & $223(139-361)$ & $187(131-274)$ & $208(131-308)$ & 0.12 \\
\hline Burkina Faso ${ }^{\mathrm{b}}$ & $234(190-279)$ & $278(201-355)$ & $192(148-235)$ & $232(200-263)$ & 0.08 \\
\hline Cameroon $^{\mathrm{c}}$ & $224(189-258)$ & $246(213-280)$ & $207(185-230)$ & $226(208-243)$ & 0.32 \\
\hline Senegal ${ }^{\mathrm{d}}$ & $238(155-322)$ & $216(146-286)$ & $240(158-323)$ & $232(189-275)$ & 0.74 \\
\hline HIV viral load $<50$ copies/mL, $n(\%)$ & $84(60.4)$ & $79(57.7)$ & $89(61.4)$ & $252(59.9)$ & 0.81 \\
\hline Burkina Faso ${ }^{\mathrm{b}}$ & $16(57.1)$ & $11(44.0)$ & $19(61.3)$ & $46(54.8)$ & 0.42 \\
\hline Cameroon $^{\mathrm{c}}$ & $68(73.9)$ & $68(71.6)$ & $70(72.2)$ & $206(72.5)$ & 0.94 \\
\hline Senegal ${ }^{\mathrm{d}}$ & $14(73.7)$ & $10(58.8)$ & $11(64.7)$ & $35(66.0)$ & 0.67 \\
\hline HIV viral load $<200$ copies/mL, $n(\%)$ & $116(83.5)$ & $119(86.9)$ & $130(89.7)$ & $365(86.7)$ & 0.31 \\
\hline Burkina Faso ${ }^{\mathrm{b}}$ & $23(82.1)$ & $19(76.0)$ & $28(90.3)$ & $70(83.3)$ & 0.36 \\
\hline Cameroon $^{\mathrm{c}}$ & $76(82.6)$ & $86(90.5)$ & $88(90.7)$ & $250(88.0)$ & 0.17 \\
\hline Senegal $^{\mathrm{d}}$ & $17(89.5)$ & $14(82.4)$ & $14(82.4)$ & $45(84.9)$ & 0.80 \\
\hline
\end{tabular}

$A B C$ ddI $L P V / r$ abacavir + didanosine + lopinavir/ritonavir, $A R T$ antiretroviral treatment, $C I$ confidence interval, $T D F / F T C D R V / r$ tenofovir/ emtricitabine + darunavir/ritonavir, $T D F / F T C L P V / r$ tenofovir/emtricitabine + lopinavir/ritonavir

*One missing value

${ }^{a}$ Chi square test for categorical variables and Mann-Whitney test for continuous variables

${ }^{\mathrm{b}} n=90$ (30 in Arm A, 28 in Arm B and 32 in Arm C)

${ }^{c} n=302$ (101 in Arm A, 99 in Arm B and 102 in Arm C)

$\mathrm{d}_{n=59}(21$ in Arm A, 18 in Arm B and 20 in Arm C)

covariates on the estimation of these probabilities are presented in Appendix 2 and Supplemental Table 4, respectively (see ESM). Similar findings to those in the basecase analysis were obtained when extrapolating outcomes to 5 years (Table 5). Cost estimations at 5 years showed that arm A remained the least costly, with mean $(95 \%$ CI) cost differences of US\$928 (566-1232) in Burkina Faso, US\$1271 (1055-1482) in Cameroon and US\$1499 (1044-1921) in Senegal for arm B vs A and US\$1184 (985-1367) in Burkina Faso, US\$1112 (917-1300) in Cameroon and US\$1245 (580-1813) in Senegal for arm $\mathrm{C}$ vs A. Health benefits were still non-significantly different between the three arms (incremental QALYs [95\% CI]: -0.079 [ -0.494 to 0.317] in Burkina Faso, 0.137 [ -0.071 to 0.349$]$ in Cameroon and -0.224 [ -0.722 to 0.283$]$ in Senegal for arm B vs A and $0.022[-0.311 ; 0.359]$ in Burkina Faso, -0.073 [ -0.283 to 0.141] in Cameroon and -0.415 [ -0.961 to 0.122] in Senegal for arm C vs A). In the three study countries, arm A had a $100 \%$ probability of being cost-effective compared with arms B and C.

\subsection{Scenarios and Prices Threshold Analysis}

The results of one-way sensitivity analysis for the basecase analysis over $24 \mathrm{M}$ and for the simulation at 5 years showed that results were robust. Irrespective of the scenario and the temporal horizon, arm A remained the preferred strategy with a probability of $100 \%$ (Tables 4,5 ). Indeed, when taking into account ARV prices observed in 2018, cost differences between arms were similar except in Senegal where they dropped for both comparisons with arms B and $\mathrm{C}$, both in $24 \mathrm{M}$ and 5-year analyses. However, the probability of arm A being cost-effective was still 100\% compared with arms B and $\mathrm{C}$ as its cost remained significantly lower (incremental costs [95\% CI] were US\$607 [542-683] and US\$1248 [858-1608] for arm B vs A over $24 \mathrm{M}$ and 5 years, respectively, and US\$419 [180-622] and US\$948 [345-1463] for arm C vs A over the same periods, respectively). When considering LYS to measure health benefits (Scenario 2) and when using an alternative sources of data for utility estimates (Scenario 3), health outcomes remained 
Table 3 Healthcare use and cost of care per patient-year (US dollars, 2016) estimated over 24 months of follow-up (ANRS 12169 2LADY, $n=451)$

\begin{tabular}{|c|c|c|c|c|}
\hline Variables & $\begin{array}{l}\text { TDF/FTC LPV/r (arm } \\
\text { A, } n=152)\end{array}$ & $\begin{array}{l}\mathrm{ABC} \text { ddI LPV/r (arm } \\
\mathrm{B}, n=145)\end{array}$ & $\begin{array}{l}\text { TDF/FTC DRV/r (arm } \\
\text { C, } n=154)\end{array}$ & $p$ value $^{\mathrm{a}}$ \\
\hline \multicolumn{5}{|l|}{ Inpatient care } \\
\hline Mean (SD) number of admissions to hospital & $0.0(0.2)$ & $0.1(0.4)$ & $0.0(0.2)$ & 0.90 \\
\hline Mean (SD) cost per patient-year & $2.9(17.0)$ & $2.6(14.9)$ & $1.4(8.3)$ & 0.59 \\
\hline \multicolumn{5}{|l|}{ Doctors outpatient consultations } \\
\hline Mean (SD) number of consultations & $6.9(0.5)$ & $6.9(0.8)$ & $6.9(1.0)$ & 0.10 \\
\hline Mean (SD) cost per patient-year & $24.0(13.5)$ & $27.5(36.1)$ & $25.6(16.6)$ & 0.99 \\
\hline \multicolumn{5}{|l|}{ Biological tests } \\
\hline Mean (SD) number of all lab tests & $81.0(7.0)$ & $80.7(11)$ & $80.6(11.6)$ & 0.78 \\
\hline Mean (SD) cost per patient-year & $352.8(78.6)$ & $399.2(452.6)$ & $366.1(157.6)$ & 0.90 \\
\hline \multicolumn{5}{|l|}{ Antiretroviral drugs (base-case analysis ${ }^{\mathbf{b}}$ ) } \\
\hline Mean (SD) cost per patient-year & $297.4(63.4)$ & $569.8(114.3)$ & $552.6(88.3)$ & $<0.0001$ \\
\hline Burkina Faso ${ }^{\mathrm{c}}$ & $279.5(6.5)$ & $515.0(50.9)$ & $524.4(44.5)$ & $<0.0001$ \\
\hline Cameroon $^{\mathrm{d}}$ & $307.2(75.1)$ & $578.4(126.8)$ & $554.9(100.1)$ & $<0.0001$ \\
\hline Senegal & $275.4(24.2)$ & $607.5(83.9)$ & $586.2(60.8)$ & $<0.0001$ \\
\hline \multicolumn{5}{|l|}{ Drugs for opportunistic infections } \\
\hline Mean (SD) number of drugs & $4.7(5.5)$ & $4.7(5.9)$ & $3.8(5.6)$ & 0.12 \\
\hline Mean (SD) cost per patient-year & $9.7(21.4)$ & $12.8(36.1)$ & $9.0(22.0)$ & 0.39 \\
\hline \multicolumn{5}{|l|}{ Total cost (base-case analysis $\left.{ }^{b}\right)$} \\
\hline Mean (SD) cost per patient-year & $686.9(112.0)$ & $1011.9(502.8)$ & $955.7(209.5)$ & $<0.0001$ \\
\hline Burkina Faso ${ }^{\mathrm{c}}$ & $566.6(41.1)$ & $834.2(137.7)$ & $805.2(40.6)$ & $<0.0001$ \\
\hline Cameroon $^{\mathrm{d}}$ & $707.1(105.1)$ & $1046.6(594.2)$ & $966.6(208.4)$ & $<0.0001$ \\
\hline Senegal & $761.7(85.7)$ & $1097.9(94.7)$ & $1140.4(212.5)$ & $<0.0001$ \\
\hline
\end{tabular}

$A B C d d I L P V / r$ abacavir + didanosine + lopinavir/ritonavir, $S D$ standard deviation, $T D F / F T C D R V / r$ tenofovir/emtricitabine + darunavir/ritonavir, $T D F / F T C L P V / r$ tenofovir/emtricitabine + lopinavir/ritonavir

${ }^{a}$ Chi square test for categorical variables, and Wilcoxon rank-sum test for continuous variables

${ }^{\mathrm{b}}$ Unit prices of antiretroviral drugs were obtained for the year 2016 from the WHO Global Price Reporting Mechanism database

${ }^{c} n=90$ (30 in arm A, 28 in arm B and 32 in arm C)

${ }^{\mathrm{d}} n=302$ (101 in arm A, 99 in arm B and 102 in arm C)

$\mathrm{e}_{n=59}(21$ in arm A, 18 in arm B and 20 in arm C)

non-significantly different between arms in any of the three study countries, both in the $24 \mathrm{M}$ and 5-year analyses. Consequently, arm A remained cost-effective with a $100 \%$ probability. Furthermore, increasing (or decreasing) the discount rate to $6 \%(0 \%)$ had little impact on the incremental costs and the LYS per patient.

Finally, the price threshold analysis showed that the price of DRV/r would have to decrease by $58 \%$ in Burkina Faso, $70 \%$ in Cameroon and $100 \%$ in Senegal to be as cost-effective as arm A; that is, to be cost-effective with a probability of 50\% (considering an unchanged $2016 \mathrm{LPV} / \mathrm{r}$ price).

\section{Discussion}

This study provides information on the economic value of bPI-based second-line ART in LMIC using data from the 2LADY trial and the post-trial cohort implemented in three countries in West and Central Africa. Besides the economic evaluation conducted alongside the trial over 2 years, we developed a simulated patient-level Markov model to assess the medium term (5-year) joint effects of ART benefits as well as factors that may affect HIV disease evolution and treatment success, together with economic factors including ARV prices.

Compared with ABC ddI LPV/r and TDF/FTC DRV/r, our findings showed that, in each study country, TDF/FTC $\mathrm{LPV} / \mathrm{r}$ was the optimal second-line treatment with a probability $\geq 95 \%$ for a large range of cost-effectiveness thresholds, irrespective of the scenarios considered. Comparisons of clinical outcomes in the short term ( 1 and 2 years) showed small differences in efficacy in terms of virological success, immune recovery, safety and tolerance [8]. Modelling and scenario analysis also suggested similar health benefits at 5 years with no significant differences observed in survival or in QALYs. However, the poorer toxic profile (especially 
Table 4 Quality-adjusted life-years (QALYs), costs (US dollars, 2016) and cost-effectiveness estimated over 24 months of follow-up (ANRS 12169 2LADY, $n=451$ )

\begin{tabular}{|c|c|c|c|c|c|}
\hline & $\begin{array}{l}\text { TDF/FTC LPV/r } \\
(\operatorname{arm~A,~} n=152) \\
\text { Mean }(95 \% \mathrm{CI})\end{array}$ & $\begin{array}{l}\text { ABC ddI LPV/r } \\
(\operatorname{arm~B,~} n=145) \\
\text { Mean }(95 \% \mathrm{CI})\end{array}$ & $\begin{array}{l}\text { TDF/FTC DRV/r } \\
(\operatorname{arm~C,~} n=154) \\
\text { Mean }(95 \% \text { CI })\end{array}$ & $\begin{array}{l}\text { Difference or ICER } \\
\text { ABC ddI LPV/r vs TDF/ } \\
\text { FTC LPV/r } \\
\text { Mean }(95 \% \text { CI })\end{array}$ & $\begin{array}{l}\text { Difference or ICER } \\
\text { TDF/FTC DRV/r vs TDF/ } \\
\text { FTC LPV/r } \\
\text { Mean }(95 \% \text { CI })\end{array}$ \\
\hline \multicolumn{6}{|l|}{ Base-case analysis } \\
\hline \multicolumn{6}{|c|}{ ARV drugs prices observed during $2016^{\mathrm{a}}$} \\
\hline \multicolumn{6}{|c|}{ Total costs per patient (USD) } \\
\hline Burkina Faso ${ }^{\mathrm{f}}$ & $1085(1056-1104)$ & $1496(1367-1584)$ & $1573(1529-1604)$ & $410(280-505)$ & $488(439-532)$ \\
\hline Cameroon $^{\mathrm{g}}$ & $1352(1308-1396)$ & $1884(1804-1961)$ & $1820(1760-1873)$ & $532(441-621)$ & $468(395-538)$ \\
\hline Senegal ${ }^{\mathrm{h}}$ & $1461(1396-1511)$ & $2183(2103-2258)$ & $2008(1751-2216)$ & $721(626-819)$ & $546(283-764)$ \\
\hline \multicolumn{6}{|c|}{ QALYs per patient ${ }^{\mathrm{b}}$} \\
\hline Burkina Faso ${ }^{\mathrm{f}}$ & $1.098(1.003-1.192)$ & $1.119(0.989-1.232)$ & $1.126(1.030-1.218)$ & $0.021(-0.140$ to 0.169$)$ & $0.028(-0.107$ to 0.162$)$ \\
\hline Cameroon $^{\mathrm{g}}$ & $1.037(0.978-1.095)$ & $1.060(1.000-1.117)$ & $0.964(0.909-1.020)$ & $0.023(-0.060$ to 0.106$)$ & $-0.073(-0.153$ to 0.008$)$ \\
\hline Senegal ${ }^{\mathrm{h}}$ & $1.201(1.078-1.309)$ & $1.063(0.920-1.207)$ & $1.022(0.853-1.177)$ & $-0.138(-0.319$ to 0.049$)$ & $-0.179(-0.381$ to 0.018$)$ \\
\hline \multicolumn{6}{|c|}{ ICER $(\Delta$ Costs/ $\Delta$ QALYs $)$} \\
\hline Burkina Faso ${ }^{\mathrm{f}}$ & & & & ICER $=19,674 *$ & ICER $=17,693 *$ \\
\hline Cameroon $^{\mathrm{g}}$ & & & & $\mathrm{ICER}=23,470^{*}$ & Arm A Dominant ${ }^{c *}$ \\
\hline Senegal ${ }^{\mathrm{h}}$ & & & & Arm A Dominant ${ }^{\mathrm{c} *}$ & Arm A Dominant ${ }^{\mathrm{c} *}$ \\
\hline \multicolumn{6}{|c|}{ Scenario 1 ( $2018 \mathrm{MSF}$ prices of $\left.A R V^{d}\right)$} \\
\hline \multicolumn{6}{|c|}{ Total costs per patient (USD) } \\
\hline Burkina Faso ${ }^{\mathrm{f}}$ & $1036(1008-1053)$ & $1457(1333-1542)$ & $1503(1462-1533)$ & $421(294-512)$ & $468(422-509)$ \\
\hline Cameroon $^{\mathrm{g}}$ & $1247(1209-1282)$ & $1752(1686-1807)$ & $1698(1645-1741)$ & $505(431-573)$ & $451(388-509)$ \\
\hline Senegal ${ }^{\mathrm{h}}$ & $1403(1338-1453)$ & 1988 (1949-2026) & $1806(1576-1993)$ & $585(520-659)$ & $402(168-602)$ \\
\hline \multicolumn{6}{|c|}{ QALYs per patient } \\
\hline Burkina Faso ${ }^{\mathrm{f}}$ & $1.098(1.003-1.192)$ & $1.119(0.989-1.232)$ & $1.126(1.030-1.218)$ & $0.021(-0.140$ to 0.169$)$ & $0.028(-0.107$ to 0.162$)$ \\
\hline Cameroon $^{\mathrm{g}}$ & $1.037(0.978-1.095)$ & $1.060(1.000-1.117)$ & $0.964(0.909-1.020)$ & $0.023(-0.060$ to 0.106$)$ & $-0.073(-0.153$ to 0.008$)$ \\
\hline Senegal & $1.201(1.078-1.309)$ & $1.063(0.920-1.207)$ & $1.022(0.853-1.177)$ & $-0.138(-0.319$ to 0.049$)$ & $-0.179(-0.381$ to 0.018$)$ \\
\hline \multicolumn{6}{|c|}{ ICER $(\Delta$ Costs/ $\Delta$ QALYs $)$} \\
\hline Burkina Faso ${ }^{\mathrm{f}}$ & & & & $\mathrm{ICER}=21,050^{*}$ & ICER $=17,682 *$ \\
\hline Cameroon $^{\mathrm{g}}$ & & & & ICER $=23,198 *$ & Arm A Dominant ${ }^{\mathrm{c} *}$ \\
\hline Senegal ${ }^{\mathrm{h}}$ & & & & Arm A Dominant ${ }^{\mathrm{c} *}$ & Arm A Dominant ${ }^{\mathrm{c} *}$ \\
\hline \multicolumn{6}{|l|}{ Scenario 2 (LYS) } \\
\hline \multicolumn{6}{|c|}{ Total costs per patient (USD) } \\
\hline Burkina Faso ${ }^{\mathrm{f}}$ & $1085(1056-1104)$ & $1496(1367-1584)$ & $1573(1529-1604)$ & $410(280-504)$ & $488(439-532)$ \\
\hline Cameroon $^{\mathrm{g}}$ & $1352(1308-1396)$ & $1884(1804-1961)$ & $1820(1760-1873)$ & $532(441-621)$ & $468(395-538)$ \\
\hline Senegal ${ }^{\mathrm{h}}$ & $1461(1396-1511)$ & $2183(2103-2258)$ & $2008(1751-2216)$ & $721(626-819)$ & $546(283-764)$ \\
\hline \multicolumn{6}{|l|}{ LYS per patient } \\
\hline Burkina Faso ${ }^{\mathrm{f}}$ & $1.898(1.820-1.944)$ & $1.823(1.657-1.930)$ & $1.921(1.888-1.939)$ & $-0.075(-0.249$ to 0.064$)$ & $0.023(-0.038$ to 0.107$)$ \\
\hline Cameroon $^{\mathrm{g}}$ & $1.882(1.825-1.928)$ & $1.892(1.823-1.946)$ & $1.901(1.842-1.945)$ & $0.009(-0.073$ to 0.088$)$ & $0.018(-0.058$ to 0.093$)$ \\
\hline Senegal ${ }^{\mathrm{h}}$ & $1.908(1.802-1.968)$ & $1.956(1.935-1.971)$ & $1.791(1.551-1.959)$ & $0.048(-0.020$ to 0.159$)$ & -0.117 ( -0.361 to 0.092$)$ \\
\hline \multicolumn{6}{|c|}{$\operatorname{ICER}(\Delta$ Costs $/ \Delta \mathrm{LYS})$} \\
\hline Burkina Faso ${ }^{\mathrm{f}}$ & & & & Arm A Dominant ${ }^{\mathrm{c} *}$ & $\mathrm{ICER}=21,048^{*}$ \\
\hline Cameroon $^{\mathrm{g}}$ & & & & $\mathrm{ICER}=56,450^{*}$ & $\mathrm{ICER}=25,729^{*}$ \\
\hline Senegal $^{\mathrm{h}}$ & & & & $\mathrm{ICER}=15,018^{*}$ & Arm A Dominant ${ }^{\mathrm{c} *}$ \\
\hline \multicolumn{6}{|c|}{ Scenario $3\left(\mathbf{Q A L Y s}^{\mathrm{e}}\right)$} \\
\hline \multicolumn{6}{|c|}{ Total costs per patient (USD) } \\
\hline Burkina Faso ${ }^{\mathrm{f}}$ & 1085 (1056-1104) & $1496(1367-1584)$ & 1573 (1529-1604) & $410(280-505)$ & $488(439-532)$ \\
\hline Cameroon $^{\mathrm{g}}$ & $1352(1308-1396)$ & $1884(1804-1961)$ & $1820(1760-1873)$ & $532(441-621)$ & $468(395-538)$ \\
\hline Senegal ${ }^{\mathrm{h}}$ & $1461(1396-1511)$ & $2183(2103-2258)$ & $2008(1751-2216)$ & $721(626-819)$ & $546(283-764)$ \\
\hline
\end{tabular}


Table 4 (continued)

$\begin{array}{lllll}\text { TDF/FTC LPV/r } & \text { ABC ddI LPV/r } & \text { TDF/FTC DRV/r } & \text { Difference or ICER } & \text { Difference or ICER } \\ (\text { arm A, } n=152) & (\text { arm B }, n=145) & (\text { arm C, } n=154) & \text { ABC ddI LPV/r vs TDF/ } & \text { TDF/FTC DRV/r vs TDF/ } \\ \text { Mean }(95 \% \text { CI) } & \text { Mean }(95 \% \text { CI }) & \text { Mean }(95 \% \text { CI }) & \text { FTC LPV/r } & \text { FTC LPV/r } \\ & & & \text { Mean }(95 \% \text { CI }) & \text { Mean }(95 \% \text { CI })\end{array}$

\begin{tabular}{|c|c|c|c|c|c|}
\hline \multicolumn{6}{|c|}{ QALYs per patient } \\
\hline Burkina Faso ${ }^{\mathrm{f}}$ & $1.611(1.534-1.678)$ & $1.581(1.428-1.692)$ & $1.632(1.571-1.688)$ & $-0.030(-0.196$ to 0.108$)$ & $0.021(-0.070$ to 0.117$)$ \\
\hline Cameroon $^{\mathrm{g}}$ & $1.564(1.508-1.613)$ & $1.584(1.521-1636)$ & $1.534(1.480-1.582)$ & $0.020(-0.059$ to 0.097$)$ & $-0.030(-0.103$ to 0.044$)$ \\
\hline Senegal $^{\mathrm{h}}$ & $1.670(1.556-1.753)$ & $1.613(1.525-1.699)$ & $1.511(1.301-1.675)$ & $-0.057(-0.182$ to 0.084$)$ & $-0.159(-0.386$ to 0.041$)$ \\
\hline \multicolumn{6}{|c|}{ ICER ( $\Delta$ Costs/ $\Delta$ QALYs $)$} \\
\hline \multicolumn{2}{|l|}{ Burkina Faso ${ }^{\mathrm{f}}$} & & & Arm A Dominant ${ }^{\mathrm{c} *}$ & ICER $=23,358^{*}$ \\
\hline \multicolumn{2}{|l|}{ Cameroon $^{\mathrm{g}}$} & & & $\mathrm{ICER}=26,716^{*}$ & Arm A Dominant ${ }^{\mathrm{c} *}$ \\
\hline \multicolumn{2}{|l|}{ Senegal $^{\mathrm{h}}$} & & & Arm A Dominant ${ }^{\mathrm{c} *}$ & Arm A Dominant ${ }^{\mathrm{c} *}$ \\
\hline \multicolumn{6}{|c|}{ Scenario $4 a$ (discount rate of $0 \%$ ) } \\
\hline \multicolumn{6}{|c|}{ Total costs per patient (USD) } \\
\hline Burkina Faso ${ }^{\mathrm{f}}$ & $1100(1069-1119)$ & $1516(1386-1607)$ & $1596(1551-1628)$ & $417(284-513)$ & $496(447-541)$ \\
\hline Cameroon $^{\mathrm{g}}$ & $1369(1324-1415)$ & 1911 (1829-1989) & $1846(1785-1900)$ & $542(449-632)$ & $477(402-548)$ \\
\hline Senegal $^{\mathrm{h}}$ & $1479(1412-1531)$ & $2214(2131-2290)$ & $2035(1773-2248)$ & $735(636-834)$ & $556(288-781)$ \\
\hline \multicolumn{6}{|c|}{ QALYs per patient } \\
\hline Burkina Faso ${ }^{\mathrm{f}}$ & $1.118(1.020-1.214)$ & $1.139(1.005-1.254)$ & $1.146(1.048-1.239)$ & $0.0214(-0.143$ to 0.174$)$ & $0.0282(-0.110$ to 0.164$)$ \\
\hline Cameroon $^{\mathrm{g}}$ & $1.056(0.995-1.115)$ & $1.079(1.019-1.138)$ & $0.981(0.925-1.038)$ & $0.0236(-0.061$ to 0.109$)$ & $-0.0743(-0.156$ to 0.008$)$ \\
\hline Senegal $^{\mathrm{h}}$ & $1.223(1.098-1.333)$ & $1.082(0.937-1.227)$ & $1.040(0.867-1.198)$ & $-0.1409(-0.324$ to 0.051$)$ & $-0.1826(-0.390$ to 0.020$)$ \\
\hline \multicolumn{6}{|c|}{ ICER $(\Delta$ Costs/ $\Delta$ QALYs $)$} \\
\hline \multicolumn{2}{|l|}{ Burkina Faso ${ }^{\mathrm{f}}$} & & & $\mathrm{ICER}=19,465^{*}$ & $\mathrm{ICER}=17,615^{*}$ \\
\hline \multicolumn{2}{|l|}{ Cameroon $^{\mathrm{g}}$} & & & $\mathrm{ICER}=22,963^{*}$ & Arm A Dominant ${ }^{\mathrm{c} *}$ \\
\hline \multicolumn{2}{|l|}{ Senegal ${ }^{\mathrm{h}}$} & & & Arm A Dominant ${ }^{\mathrm{c} *}$ & Arm A Dominant ${ }^{\mathrm{c} *}$ \\
\hline \multicolumn{6}{|c|}{ Scenario $4 b$ (discount rate of $6 \%$ ) } \\
\hline \multicolumn{6}{|c|}{ Total costs per patient (USD) } \\
\hline Burkina Faso ${ }^{\mathrm{f}}$ & $1076(1047-1094)$ & $1482(1354-1569)$ & $1558(1515-1589)$ & $406(275-499)$ & $482(434-526)$ \\
\hline Cameroon $^{\mathrm{g}}$ & $1340(1297-1384)$ & $1866(1787-1942)$ & $1803(1744-1855)$ & $526(436-613)$ & $463(390-531)$ \\
\hline Senegal ${ }^{\mathrm{h}}$ & 1449 (1386-1498) & $2162(2082-2236)$ & 1989 (1735-2197) & $713(617-809)$ & $540(278-755)$ \\
\hline \multicolumn{6}{|c|}{ QALYs per patient } \\
\hline Burkina Faso ${ }^{\mathrm{f}}$ & $1.085(0.991-1.178)$ & $1.106(0.976-1.217)$ & $1.113(1.018-1.203)$ & $0.0205(-0.139$ to 0.168$)$ & $0.0272(-0.105$ to 0.157$)$ \\
\hline Cameroon $^{\mathrm{g}}$ & $1.025(0.966-1.082)$ & $1.047(0.988-1.104)$ & $0.952(0.898-1.007)$ & $0.0221(-0.059$ to 0.105$)$ & $-0.0723(-0.151$ to 0.008$)$ \\
\hline Senegal ${ }^{\mathrm{h}}$ & $1.186(1.066-1.294)$ & $1.050(0.910-1.193)$ & $1.009(0.843-1.164)$ & $-0.1364(-0.317$ to 0.050$)$ & $-0.1767(-0.376$ to 0.018$)$ \\
\hline \multicolumn{6}{|c|}{ ICER ( $\Delta$ Costs/ $\Delta$ QALYs $)$} \\
\hline Burkina Faso ${ }^{\mathrm{f}}$ & & & & $\mathrm{ICER}=19,823^{*}$ & $\mathrm{ICER}=17,750^{*}$ \\
\hline Cameroon $^{\mathrm{g}}$ & & & & $\mathrm{ICER}=23,834 *$ & Arm A Dominant ${ }^{\mathrm{c} *}$ \\
\hline Senegal ${ }^{\mathrm{h}}$ & & & & Arm A Dominant ${ }^{\mathrm{c} *}$ & Arm A Dominant ${ }^{\mathrm{c} *}$ \\
\hline
\end{tabular}

$A B C$ ddI $L P V / r$ abacavir + didanosine + lopinavir/ritonavir, $A R V$ antiretroviral drugs, $C I$ confidence interval, $I C E R$ incremental cost-effectiveness ratio, $L Y S$ life-year saved, $M S F$ Médecins Sans Frontières, $Q A L Y s$ quality-adjusted life-years, TDF/FTC DRV/r tenofovir/emtricitabine + darunavir/ritonavir, TDF/FTC LPV/r tenofovir/emtricitabine + lopinavir/ritonavir, USD United States dollars, $\triangle$ difference

*The probability of arm A being cost-effective at one times the country's per capita gross domestic product is $100 \%$

${ }^{a}$ Unit prices of antiretroviral drugs for the year 2016 (obtained from the WHO Global Price Reporting Mechanism database)

${ }^{b}$ Estimates of utilities were obtained from the DART trial [16]

${ }^{\mathrm{c}}$ Dominance means significant lower costs and higher QALYs

${ }^{\mathrm{d}}$ Unit prices of antiretroviral drugs for the year 2018 (obtained from the Médecins Sans Frontières report [30]

${ }^{\mathrm{e}}$ Estimates of utilities were obtained from Tengs and Lin [31]

${ }^{\mathrm{f}} n=90$ (30 in arm A, 28 in arm B and 32 in arm C)

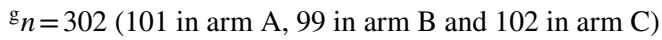

${ }^{\mathrm{h}} n=59$ (21 in arm A, 18 in arm B and 20 in arm C) 

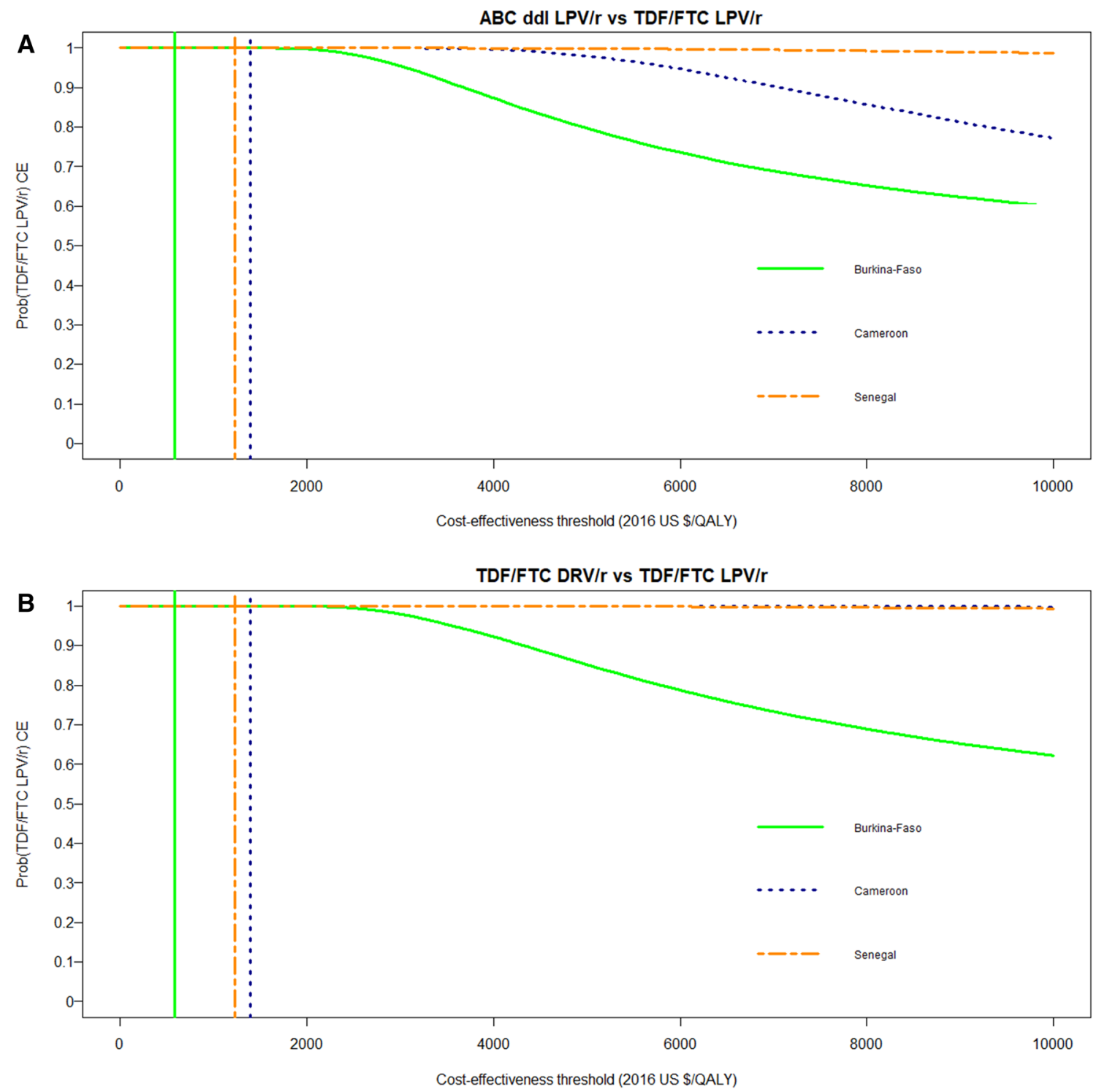

Fig. 1 Cost-effectiveness acceptability curves of TDF/FTC LPV/r compared with $\mathrm{ABC}$ ddI LPV/r (a) and compared with TDF/FTC $\mathrm{DRV} / \mathrm{r}$ (b) in the ANRS 12169 2LADY trial. The coloured vertical lines indicate the cost-effectiveness thresholds of 1 times the GDP/ capita in 2016 for each of the three study countries (i.e. US\$584 in Burkina Faso, US\$1392 in Cameroon and US\$1231 in Senegal). The cost-effectiveness acceptability curves show the probability that TDF/ FTC LPV/r is cost-effective compared with ABC ddI LPV/r (a) and with TDF/FTC DRV/r (b) in each of the three study countries over a

in terms of neuropathy), more complicated schedule and lack of advantages in terms of efficacy of the combination with $\mathrm{ABC}$ ddI, argue for its elimination from WHO recommendations [8]. With regard to costs, TDF/FTC LPV/r was significantly less costly than the other two strategies. When considering ARV prices observed during 2015-2016, TDF/ FTC LPV/r saved between US\$410 (in Burkina Faso) and US\$721 (in Senegal) per patient over $24 \mathrm{M}$, compared with the $\mathrm{ABC}$ ddI LPV/r regimen, and US\$468 (in Cameroon) range of values for the cost-effectiveness threshold $\lambda$ (i.e. the maximum amount that the decision maker is willing to pay for one unit of health). $A B C d d I L P V / r$ abacavir + didanosine + lopinavir/ritonavir, Prob(TDF/FTC LPV/rCE) probability of TDF/FTC LPV/r being cost-effective at one times the country's per-capita gross domestic product, $Q A L Y s$ quality-adjusted life-years, TDF/FTC $D R V / r$ tenofovir/emtricitabine + darunavir/ritonavir, TDF/FTC $L P V / r$ tenofovir/ emtricitabine + lopinavir/ritonavir

to US\$546 (in Senegal) over the same period compared with the DRV/r-based regimen. These cost differences were driven by the lower cost of ARV in the TDF/FTC LPV/r regimen compared with the two other regimens, due to lower monthly prices both of the two NRTI drugs (TDF/FTC vs ABC ddI) and of the bPI (LPV/r vs DRV/r). The largest cost differences were in Senegal as ARV prices were relatively higher there than in the two other countries, especially for ABC ddI and DRV/r. When considering ARV prices in 
Table 5 Extrapolation to 5 years of quality-adjusted life-years (QALYs), costs (US dollars, 2016) and cost-effectiveness (ANRS 12169 2LADY, $n=451$ )

\begin{tabular}{|c|c|c|c|c|c|}
\hline & $\begin{array}{l}\text { TDF/FTC LPV/r } \\
(\operatorname{arm~A,~} n=152) \\
\text { Mean }(95 \% \mathrm{CI})\end{array}$ & $\begin{array}{l}\text { ABC ddI LPV/r } \\
(\operatorname{arm~B,~} n=145) \\
\text { Mean }(95 \% \mathrm{CI})\end{array}$ & $\begin{array}{l}\text { TDF/FTC DRV/r } \\
(\operatorname{arm~C}, n=154) \\
\text { Mean }(95 \% \mathrm{CI})\end{array}$ & $\begin{array}{l}\text { Difference or ICER } \\
\text { ABC ddI LPV/r vs TDF/ } \\
\text { FTC LPV/r } \\
\text { Mean }(95 \% \text { CI) }\end{array}$ & $\begin{array}{l}\text { Difference or ICER } \\
\text { TDF/FTC DRV/r vs TDF/ } \\
\text { FTC LPV/r } \\
\text { Mean }(95 \% \text { CI) }\end{array}$ \\
\hline \multicolumn{6}{|c|}{ Base-case over 5 years ${ }^{\text {a }}$} \\
\hline \multicolumn{6}{|c|}{ Total costs per patient (USD) } \\
\hline Burkina Faso ${ }^{\mathrm{f}}$ & 2185 (2040-2282) & $3113(2772-3384)$ & 3369 (3209-3462) & $928(566-1232)$ & $1184(985-1367)$ \\
\hline Cameroon $^{\mathrm{g}}$ & $2674(2553-2795)$ & $3946(3763-4115)$ & $3786(3631-3926)$ & $1271(1055-1482)$ & $1112(917-1300)$ \\
\hline Senegal $^{\mathrm{h}}$ & $2804(2548-2988)$ & $4303(3893-4638)$ & 4049 (3411-4567) & $1499(1044-1921)$ & $1245(580-1813)$ \\
\hline \multicolumn{6}{|c|}{ QALYs per patient ${ }^{\mathrm{b}}$} \\
\hline Burkina Faso ${ }^{\mathrm{f}}$ & $2.759(2.494-2.989)$ & $2.679(2.338-2.972)$ & $2.781(2.547-2.990)$ & $-0.079(-0.494$ to 0.317$)$ & $0.022(-0.311$ to 0.359$)$ \\
\hline Cameroon $^{\mathrm{g}}$ & $2.582(2.419-2.736)$ & $2.719(2.576-2.850)$ & $2.508(2.363-2.646)$ & $0.137(-0.071$ to 0.349$)$ & $-0.073(-0.283$ to 0.141$)$ \\
\hline Senegal ${ }^{\mathrm{h}}$ & $2.879(2.520-3.166)$ & $2.655(2.257-3.008)$ & $2.464(2.015-2.860)$ & $-0.224(-0.722$ to 0.283$)$ & -0.415 ( -0.961 to 0.122$)$ \\
\hline \multicolumn{6}{|c|}{ ICER $(\Delta$ Costs/ $\Delta$ QALYs $)$} \\
\hline Burkina Faso ${ }^{\mathrm{f}}$ & & & & Arm A Dominant ${ }^{\mathrm{c} *}$ & ICER $=53,354 *$ \\
\hline Cameroon $^{\mathrm{g}}$ & & & & $\mathrm{ICER}=9273^{*}$ & Arm A Dominant ${ }^{\mathrm{c} *}$ \\
\hline Senegal $^{\mathrm{h}}$ & & & & Arm A Dominant ${ }^{\mathrm{c} *}$ & Arm A Dominant ${ }^{\mathrm{c} *}$ \\
\hline \multicolumn{6}{|c|}{ Scenario 1 ( 2018 MSF prices of $\left.A R V^{d}\right)$} \\
\hline \multicolumn{6}{|c|}{ Total costs per patient (USD) } \\
\hline Burkina Faso ${ }^{\mathrm{f}}$ & $2072(1935-2163)$ & $3025(2695-3288)$ & $3208(3056-3296)$ & $953(603-1245)$ & $1136(947-1309)$ \\
\hline Cameroon $^{\mathrm{g}}$ & 2425 (2324-2517) & $3652(3503-3775)$ & $3500(3364-3615)$ & $1227(1053-1389)$ & $1075(912-1231)$ \\
\hline Senegal ${ }^{\mathrm{h}}$ & $2667(2426-2843)$ & $3867(3535-4117)$ & $3577(3019-4028)$ & $1200(820-1551)$ & $910(322-1413)$ \\
\hline \multicolumn{6}{|l|}{ QALYs per patient } \\
\hline Burkina Faso ${ }^{\mathrm{f}}$ & $2.759(2.494-2.989)$ & $2.679(2.338-2.972)$ & $2.781(2.547-2.990)$ & $-0.079(-0.494$ to 0.317$)$ & $0.022(-0.311$ to 0.359$)$ \\
\hline Cameroon $^{\mathrm{g}}$ & $2.582(2.419-2.736)$ & $2.719(2.576-2.850)$ & $2.508(2.363-2.646)$ & $0.137(-0.071$ to 0.349$)$ & $-0.073(-0.283$ to 0.141$)$ \\
\hline Senegal $^{\mathrm{h}}$ & $2.879(2.520-3.166)$ & $2.655(2.257-3.008)$ & $2.464(2.015-2.860)$ & $-0.224(-0.722$ to 0.283$)$ & $-0.415(-0.961$ to 0.122$)$ \\
\hline \multicolumn{6}{|c|}{ ICER $(\Delta$ Costs/ $\Delta$ QALYs $)$} \\
\hline Burkina Faso ${ }^{\mathrm{f}}$ & & & & Arm A Dominant ${ }^{\mathrm{c} *}$ & $\mathrm{ICER}=53,276^{*}$ \\
\hline Cameroon $^{\mathrm{g}}$ & & & & $\mathrm{ICER}=9318^{*}$ & Arm A Dominant ${ }^{\mathrm{c} *}$ \\
\hline Senegal ${ }^{\mathrm{h}}$ & & & & Arm A Dominant ${ }^{\mathrm{c} *}$ & Arm A Dominant ${ }^{\mathrm{c} *}$ \\
\hline \multicolumn{6}{|l|}{ Scenario 2 (LYS) } \\
\hline \multicolumn{6}{|c|}{ Total costs per patient (USD) } \\
\hline Burkina Faso ${ }^{\mathrm{f}}$ & 2185 (2040-2282) & $3113(2772-3384)$ & $3369(3209-3462)$ & $928(566-1232)$ & $1184(985-1367)$ \\
\hline Cameroon $^{\mathrm{g}}$ & $2674(2553-2795)$ & $3946(3763-4115)$ & $3786(3631-3926)$ & $1271(1055-1482)$ & $1112(917-1300)$ \\
\hline Senegal ${ }^{\mathrm{h}}$ & $2804(2548-2988)$ & 4303 (3893-4638) & 4049 (3411-4567) & $1499(1044-1921)$ & $1245(580-1813)$ \\
\hline \multicolumn{6}{|l|}{ LYS per patient } \\
\hline Burkina Faso ${ }^{\mathrm{f}}$ & $4.322(3.985-4.546)$ & $4.137(3.672-4.520)$ & $4.429(4.225-4.540)$ & $-0.185(-0.721$ to 0.309$)$ & $0.106(-0.214$ to 0.468$)$ \\
\hline Cameroon $^{\mathrm{g}}$ & $4.267(4.075-4.436)$ & $4.357(4.181-4.494)$ & $4.313(4.138-4.457)$ & $0.090(-0.151$ to 0.334$)$ & $0.045(-0.195$ to 0.291$)$ \\
\hline Senegal ${ }^{\mathrm{h}}$ & $4.248(3.778-4.561)$ & $4.320(3.975-4.559)$ & $3.998(3.347-4.546)$ & $0.072(-0.412$ to 0.606$)$ & $-0.249(-0.991$ to 0.444$)$ \\
\hline \multicolumn{6}{|c|}{$\operatorname{ICER}(\Delta$ Costs $/ \Delta \mathrm{LYS})$} \\
\hline Burkina Faso ${ }^{\mathrm{f}}$ & & & & Arm A Dominant ${ }^{\mathrm{c} *}$ & ICER $=11,147^{*}$ \\
\hline Cameroon $^{\mathrm{g}}$ & & & & $\mathrm{ICER}=14,150 *$ & ICER $=24,544 *$ \\
\hline Senegal $^{\mathrm{h}}$ & & & & $\mathrm{ICER}=20,778^{*}$ & Arm A Dominant ${ }^{\mathrm{c} *}$ \\
\hline \multicolumn{6}{|c|}{ Scenario $3\left(\right.$ QALYs $\left.^{\mathbf{e}}\right)$} \\
\hline \multicolumn{6}{|c|}{ Total costs per patient (USD) } \\
\hline Burkina Faso ${ }^{\mathrm{f}}$ & 2185 (2040-2282) & $3113(2772-3384)$ & 3369 (3209-3462) & $928(566-1232)$ & $1184(985-1367)$ \\
\hline Cameroon $^{\mathrm{g}}$ & $2674(2553-2795)$ & $3946(3763-4115)$ & $3786(3631-3926)$ & $1271(1055-1482)$ & $1112(917-1300)$ \\
\hline Senegal $^{\mathrm{h}}$ & $2804(2548-2988)$ & $4303(3893-4638)$ & $4049(3411-4567)$ & $1499(1044-1921)$ & $1245(580-1813)$ \\
\hline
\end{tabular}


Table 5 (continued)

\begin{tabular}{|c|c|c|c|c|c|}
\hline & $\begin{array}{l}\text { TDF/FTC LPV/r } \\
(\operatorname{arm~A,~} n=152) \\
\text { Mean }(95 \% \mathrm{CI})\end{array}$ & $\begin{array}{l}\text { ABC ddI LPV/r } \\
(\operatorname{arm~B,} n=145) \\
\text { Mean }(95 \% \mathrm{CI})\end{array}$ & $\begin{array}{l}\text { TDF/FTC DRV/r } \\
(\operatorname{arm~C}, n=154) \\
\text { Mean }(95 \% \mathrm{CI})\end{array}$ & $\begin{array}{l}\text { Difference or ICER } \\
\text { ABC ddI LPV/r vs TDF/ } \\
\text { FTC LPV/r } \\
\text { Mean }(95 \% \text { CI })\end{array}$ & $\begin{array}{l}\text { Difference or ICER } \\
\text { TDF/FTC DRV/r vs TDF/ } \\
\text { FTC LPV/r } \\
\text { Mean }(95 \% \text { CI })\end{array}$ \\
\hline \multicolumn{6}{|c|}{ QALYs per patient } \\
\hline Burkina Faso ${ }^{\mathrm{f}}$ & $3.803(3.499-4.032)$ & $3.660(3.240-3.998)$ & $3.871(3.654-4.026)$ & $-0.142(-0.634$ to 0.310$)$ & $0.068(-0.253$ to 0.415$)$ \\
\hline Cameroon $^{\mathrm{g}}$ & $3.670(3.492-3.829)$ & $3.797(3.636-3.930)$ & $3.663(3.502-3.803)$ & $0.127(-0.097$ to 0.354$)$ & $-0.007(-0.233$ to 0.225$)$ \\
\hline Senegal $^{\mathrm{h}}$ & $3.817(3.391-4.134)$ & $3.730(3.346-4.037)$ & $3.472(2.895-3.939)$ & $-0.086(-0.593$ to 0.444$)$ & $-0.344(-1.0 .18$ to 0.290$)$ \\
\hline \multicolumn{6}{|c|}{$\operatorname{ICER}(\Delta$ Costs/ $\Delta$ QALYs $)$} \\
\hline Burkina Faso ${ }^{\mathrm{f}}$ & & & & Arm A Dominant ${ }^{\mathrm{c} *}$ & $\mathrm{ICER}=17,398^{*}$ \\
\hline Cameroon $^{\mathrm{g}}$ & & & & $\mathrm{ICER}=10,011^{*}$ & Arm A Dominant ${ }^{\mathrm{c} *}$ \\
\hline Senegal $^{\mathrm{h}}$ & & & & Arm A Dominant ${ }^{\mathrm{c} *}$ & Arm A Dominant ${ }^{\mathrm{c} *}$ \\
\hline \multicolumn{6}{|c|}{ Scenario 4a (discount rate of $0 \%$ ) } \\
\hline \multicolumn{6}{|c|}{ Total costs per patient (USD) } \\
\hline Burkina Faso ${ }^{\mathrm{f}}$ & $2317(2158-2423)$ & $3305(2938-3598)$ & $3582(3409-3683)$ & $988(598-1318)$ & $1265(1048-1465)$ \\
\hline Cameroon $^{\mathrm{g}}$ & $2834(2702-2965)$ & $4193(3997-4374)$ & $4023(3856-4174)$ & $1359(1126-1585)$ & $1189(978-1393)$ \\
\hline Senegal $^{\mathrm{h}}$ & $2969(2688-3170)$ & $4562(4110-4929)$ & $4296(3610-4855)$ & $1593(1092-2055)$ & $1327(609-1938)$ \\
\hline \multicolumn{6}{|c|}{ QALYs per patient } \\
\hline Burkina Faso ${ }^{\mathrm{f}}$ & $2.954(2.666-3.202)$ & $2.862(2.494-3.177)$ & $2.974(2.723-3.198)$ & $-0.092(-0.539$ to 0.337$)$ & $0.020(-0.338$ to 0.384$)$ \\
\hline Cameroon $^{\mathrm{g}}$ & $2.764(2.588-2.930)$ & $2.915(2.761-3.056)$ & $2.690(2.533-2.838)$ & $0.150(-0.074$ to 0.378$)$ & $-0.075(-0.301$ to 0.156$)$ \\
\hline Senegal $^{\mathrm{h}}$ & $3.079(2.688-3.391)$ & $2.843(2.412-3.222)$ & $2.636(2.152-3.063)$ & $-0.237(-0.778$ to 0.312$)$ & $-0.444(-1.034$ to 0.137$)$ \\
\hline \multicolumn{6}{|c|}{ ICER $(\Delta \operatorname{Costs} / \Delta \mathrm{QALYs})$} \\
\hline Burkina Faso ${ }^{\mathrm{f}}$ & & & & Arm A Dominant ${ }^{\mathrm{c} *}$ & $\mathrm{ICER}=62,198^{*}$ \\
\hline Cameroon $^{\mathrm{g}}$ & & & & $\mathrm{ICER}=9047 *$ & Arm A Dominant ${ }^{\mathrm{c} *}$ \\
\hline Senegal ${ }^{\mathrm{h}}$ & & & & Arm A Dominant ${ }^{\mathrm{c} *}$ & Arm A Dominant ${ }^{\mathrm{c} *}$ \\
\hline \multicolumn{6}{|c|}{ Scenario $4 \mathrm{~b}$ (discount rate of $6 \%$ ) } \\
\hline \multicolumn{6}{|c|}{ Total costs per patient (USD) } \\
\hline Burkina Faso ${ }^{\mathrm{f}}$ & $2101(1964-2192)$ & $2991(2666-3248)$ & $3233(3082-3322)$ & $890(547-1178)$ & $1133(945-1305)$ \\
\hline Cameroon $^{\mathrm{g}}$ & $2572(2457-2687)$ & 3788 (3614-3949) & $3638(3491-3770)$ & $1216(1009-1416)$ & $1065(880-1243)$ \\
\hline Senegal $^{\mathrm{h}}$ & $2699(2459-2873)$ & $4138(3754-4452)$ & $3888(3281-4379)$ & $1439(1012-1834)$ & $1189(556-1726)$ \\
\hline \multicolumn{6}{|c|}{ QALYs per patient } \\
\hline Burkina Faso ${ }^{\mathrm{f}}$ & $2.634(2.384-2.853)$ & $2.563(2.238-2.840)$ & $2.657(2.434-2.857)$ & $-0.071(-0.466$ to 0.304$)$ & $0.023(-0.294$ to 0.344$)$ \\
\hline Cameroon $^{\mathrm{g}}$ & $2.466(2.311-2.612)$ & $2.594(2.458-2.720)$ & $2.393(2.255-2.524)$ & $0.129(-0.0689$ to 0.330$)$ & $-0.073(-0.272$ to 0.131$)$ \\
\hline Senegal ${ }^{\mathrm{h}}$ & $2.751(2.411-3.022)$ & $2.535(2.158-2.871)$ & $2.355(1.929-2.731)$ & $-0.216(-0.687$ to 0.264$)$ & $-0.396(-0.914$ to 0.112$)$ \\
\hline \multicolumn{6}{|c|}{ ICER $(\Delta$ Costs/ $\Delta$ QALYs $)$} \\
\hline Burkina Faso ${ }^{\mathrm{f}}$ & & & & Arm A Dominant ${ }^{\mathrm{c} *}$ & $\mathrm{ICER}=48,690^{*}$ \\
\hline Cameroon $^{\mathrm{g}}$ & & & & $\mathrm{ICER}=9439 *$ & Arm A Dominant ${ }^{\mathrm{c} *}$ \\
\hline Senegal $^{\mathrm{h}}$ & & & & Arm A Dominant ${ }^{\mathrm{c} *}$ & Arm A Dominant ${ }^{\mathrm{c} *}$ \\
\hline
\end{tabular}

$A B C$ ddI $L P V / r$ abacavir + didanosine + lopinavir/ritonavir, $A R V$ antiretroviral drugs, $C I$ confidence interval, $I C E R$ incremental cost-effectiveness ratio, $L Y S$ life-year saved, MSF Médecins Sans Frontières, $Q A L Y s$ quality-adjusted life-years, TDF/FTC DRV/r tenofovir/emtricitabine + darunavir/ritonavir, TDF/FTC $L P V / r$ tenofovir/emtricitabine + lopinavir/ritonavir, USD United States dollars, $\triangle$ difference

*The probability of arm A being cost-effective at one times the country's per capita gross domestic product is $100 \%$

${ }^{a}$ Unit prices of antiretroviral drugs for the year 2016 (obtained from the WHO Global Price Reporting Mechanism database)

${ }^{b}$ Estimates of utilities were obtained from the DART trial [16]

${ }^{\mathrm{c}}$ Dominance means lower costs and higher QALYs

${ }^{\mathrm{d}}$ Unit prices of antiretroviral drugs for the year 2018 (obtained from the Médecins Sans Frontières report [30]

${ }^{\mathrm{e}}$ Estimates of utilities were obtained from Tengs and Lin [31]

${ }^{\mathrm{f}} n=90$ (30 in arm A, 28 in arm B and 32 in arm C)

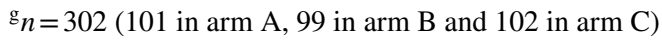

$\mathrm{h}_{n=59}(21$ in arm A, 18 in arm B and 20 in arm C) 
2018, cost differences between the three second-line regimens were similar, except for Senegal where we observed a significant decrease. Indeed, the prices of ABC ddI and $\mathrm{DRV} / \mathrm{r}$ drugs there were higher than those reported by MSF for LMIC in 2018. This was not the case in Burkina Faso or Cameroon where ARV prices observed in 2016 were comparable with those of MSF.

A number of studies have been conducted in highincome settings on the cost-effectiveness of LPV/r-based regimens used either in first-line, second-line or simplified (mono and dual) therapy [32-34]. Although they compared LPV/r with alternative regimens to ours, all showed that LPV/r-based regimens may result in cost-saving and yet deliver similar clinical outcomes. In LMIC, one study has assessed the costs of second-line treatments and found an average yearly cost of US\$1037 per patient, which is comparable with our estimations of US\$687-1012 per patient-year [35]. Another study that compared the costeffectiveness of a simplified second-line therapy using lopinavir/ritonavir + raltegravir with $\mathrm{LPV} / \mathrm{r}+2 \mathrm{NRTIs}$ concluded that this novel strategy could be cost-effective for upper-middle income countries but not for LMIC like Nigeria [14].

The 2018 updated WHO guidelines recommend the use of DTG in combination with a two-NRTI backbone as the second-line option for PLHIV with first-line virological failure on efavirenz- or nevirapine-based regimens [5]. Indeed, recent evidence provided by the DAWNING trial showed that DTG-based regimens were superior to LPV/r-based regimens, virological success ( $\mathrm{VL}<50$ copies $/ \mathrm{mL}$ ) being achieved in $78 \%$ vs $69 \%$ of participants with first-line failure [36]. Despite the benefits of DTG, its use in second-line therapy in LMIC raises some concerns [37, 38]. In particular, DTG-based regimens are not currently recommended for women of reproductive age due to potentially higher risk of neural tube defects in children born to women who initiated DTG before conception [39]. A recent modelling study suggests, however, that the risk associated with DTG exposure to foetuses is outweighed by the reduction in mother-to-child HIV transmission due to the higher probability of viral suppression with this regimen [40]. Furthermore, thanks to a recent pricing agreement, a generic fixed-dose combination of TDF/3TC/DTG will be provided in LMIC at a cost of approximately US\$75 per person per year [41]. At this price, this regimen should be very cost-effective compared with LPV/r-based regimens, which are currently almost six times more expensive. While DTG-based regimens should provide greater economic value than LPV/r-based regimens, alternative bPI-based second-line therapies are still needed in LMIC, especially for patients who will receive DTG in first-line treatment.

This study has limitations. First, QALYs were estimated in the base-case analysis using utility estimates derived from the literature, as data were not available in the trial or post-trial data $[16,31]$. The utility values used in the base-case analysis were estimated using preference-based methods from a large sample of patients within the DART (Development of Anti-Retroviral Therapy in Africa) trial in Uganda [16]. In scenario analysis, we also considered an alternative source of data, specifically a meta-analysis pooling data from studies conducted in high-income countries [31]. QALYs per patient were still not significantly different between arms, and consequently, TDF/FTC LPV/r remained the optimal second-line therapy. Second, the structure of the simulated patient-level Markov model and the definition of heath states were constrained by the size of the study population, which was too small to consider a larger number of health states. In particular, we were not able to consider an additional health state for patients with $\mathrm{CD} 4<50$ cells/ $\mathrm{mL}$ or define health states by combining CD4 cell count and VL as the model did not converge due to an insufficient number of transitions observed. However, the effect of virological failure on disease progression was taken into account through the introduction of this variable in the model used to estimate transition probabilities. In addition, our model does not account for HIV transmission. Although we recognise that dynamic models are the most suitable to assess long-term public health impacts in the field of HIV, we believe that for our study purpose, such a model was not indispensable as the alternative regimens considered in the analysis offered very similar benefits, including benefits in terms of virological suppression. Not taking into account HIV transmission may have led to an underestimation of health benefits for each strategy, but it is unlikely to have biased our cost-effectiveness results as a similar number of HIV transmissions are expected to occur in the three alternative second-line regimens assessed. Finally, our study was conducted using data collected in a trial setting, which may limit the generalisability of the results. Nevertheless, this study included PLHIV followed in the largest HIV treatment centres of the three study countries. It is therefore likely that the trial population reflected patients switching to secondline treatment in real-life contexts where viral load monitoring and genotyping are generally not available [8].

\section{Conclusion}

Despite the recent changes to WHO guidelines, our findings remain relevant considering the need for bPI-based secondline combinations as alternatives to DTG-based regimens. We showed that despite their clinical similarities, the choice of the bPI-based second-line ART combinations will have different economic consequences because of large differences in the monthly costs of ARV. As ARV costs are the 
main driver of HIV healthcare costs over the long term, it is essential that decision makers give priority to regimens that provide the best economic value. Our findings showed that at recent ARV prices, using TDF/FTC LPV/r as a bPIbased second-line regimen may be the most efficient use of resources in LMIC, supporting the choices made by WHO in its 2018 guidelines.

Acknowledgements We thank the ANRS 12169 2LADY trial participants and their partners, families, and caregivers, as well as the staff of all the participating sites. Our thanks also to the ANRS (Agence Nationale de Recherche sur le SIDA) for its support, to Gwenaëlle Maradan for its monitoring of the economic data collection and to Jude Sweeney for the English revision and editing of the manuscript.

Members of the ANRS 12169 2LADY Study Group

Protocol Steering Committee: E. Delaporte, S. Koulla-Shiro, C.T. Ndour, A. Sawadogo, V. Le Moing, J. Reynes, A. Calmy, L. Ciaffi, P.M. Girard, S. Eholie, M.L. Chaix, C. Kouanfack, I. Tita, B. Bazin, P. Garcia, J.B. Guiard-Schmid. Project Team: V. Le Moing, S. Izard, S. Eymard-Duvernay, L. Ciaffi, M. Peeters, L. Serrano, A. Cournil, I. Diallo, E. Delaporte. Site Investigators: J.M. Mben, R. Toby, N. Manga, L. Ayangma, B. Taman, F.N. Kabore, E. Kamboule, J. Zoungrana, A. Diouf, M. Diallo, L. Fortes, N.F. Ngom Gueye, G. Batista.

Site Staff: A. Aghokeng, E. Guichet, H. Abessolo, C. Essomba, G. Manirakiza, F. Essomba, T. Mbarga, S. Epanda, A. Bikie, T. Nke, N. Massaha, E. Nke, M. Ngolle, D. Bikobo, L. Abologo, O. Elat, G. Laborde-Balen, A. Diouf, A. Diop, B. Diouf, N. Bara, M.B. Koita Fall, C. Toure Kane, F.B. Seck, S. Ba, P. Njantou, A. Ndyaye, A. Hema, P. Fao, P. Ouedrago, R. Traore, Y. Sanou, G. Bado, M. Coulibaly, E. Some, J. Some, A. Kambou, A. Tapsoba, D. Sombie, S. Sanou, B. Traore. Data and Safety Monitoring Board: P. Flandre, C. Michon, J. Drabo, F. Simon.

Author Contributions ED, SK-S and LC contributed to the conception and design of the ANRS 12169 2LADY trial and overviewed the trial implementation. CK, AS, RT, MPM-E and NFNG participated in the clinical follow-up of the participants and were responsible for clinical data collection. SB designed the health economic study and overviewed the economic study. LM and MLN built the costing database. MLN performed the economic analysis, prepared figures and tables and participated in the interpretation of the data. SB and LS-T supervised the data analysis. The manuscript was drafted by SB. All authors contributed to the interpretation of the data, revised the article critically for important intellectual content, and approved the final version of the manuscript for submission.

The corresponding author had full access to all the data in the study and had final responsibility for the decision to submit for publication.

Data Availability The datasets generated and analysed during the current study as well as the model underpinning our research are available from the corresponding author on reasonable request.

\section{Compliance with Ethical Standards}

Ethics committee The participating countries' national Ethic Committees approved the protocol for the economic evaluation study and the protocol of the trial. In addition, the trial protocol was approved by the institutional Ethics Committee of the Institut de Recherche pour le Développement (IRD) in France. All participants provided written informed consent. The study was conducted in accordance with the Declaration of Helsinki and the Good Clinical Practice Guidelines. The trial is registered with ClinicalTrial.gov with the number NCT00928187.
Conflict of interest L.C, S.K-S and A.S report grants from ANRS with financial support by Janssen Pharmaceuticals. E.D, C.K, R.T, N.F.N.G, S.B, L.M, M.L.N, L.S-T, M.A.B, M.P.M-E and B.S report no conflict of interest in relation to this study.

Source of support This work was supported by the Agence National de Recherche sur le SIDA-Inserm ANRS (Grant number 12231). The trial was sponsored by Agence National de Recherche sur le SIDAInserm ANRS (Grant number 12169) and by European and Developing Countries Clinical Trials Partnership (EDCTP) (Grant number IP.2007.33011.004). Gilead Sciences and Janssen provided study drugs, the latter partially funding the study. Neither firm had any role in the study design, data collection, data analysis, data interpretation or writing of the report.

Open Access This article is distributed under the terms of the Creative Commons Attribution-NonCommercial 4.0 International License (http://creativecommons.org/licenses/by-nc/4.0/), which permits any noncommercial use, distribution, and reproduction in any medium, provided you give appropriate credit to the original author(s) and the source, provide a link to the Creative Commons license, and indicate if changes were made.

\section{References}

1. World Health Organization. WHO HIV update: global epidemic, progress in scale up and policy uptake [Internet]; 2018. http://www.who.int/hiv/data/2017_global_summary_web_v11. pptx?ua=1. Accessed 23 Oct 2018.

2. World Health Organization, Habiyambere V. WHO global ARVs and diagnostic use survey in 2015 in low and middle-income countries [Internet]; 2016. http://www.who.int/hiv/amds/amds2 016-ppt-WHO-2015ARVUseSurvey.pdf. Accessed 23 Oct 2018.

3. Onoya D, Nattey C, Budgell E, van den Berg L, Maskew M, Evans D, et al. Predicting the need for third-line antiretroviral therapy by identifying patients at high risk for failing second-line antiretroviral therapy in South Africa. AIDS Patient Care STDs. 2017;31:205-12.

4. Consolidated guidelines on the use of antiretroviral drugs for treating and preventing HIV infection: recommendations for a public health approach [Internet]; 2016. http://www.deslibris.ca/ ID/10089566. Accessed 11 Sept 2018.

5. World Health Organization, Haile-Selassie H, World Health Organization, Department of HIV/AIDS, Centers for Disease Control and Prevention (U.S.), Global Fund to Fight AIDS T and Malaria, et al. WHO HIV drug resistance report 2017 [Internet]; 2017. http://apps.who.int/iris/bitstream/10665/255896/1/97892 41512831-eng.pdf. Accessed 11 Sept 2018.

6. Murphy RA, Court R, Maartens G, Sunpath H. Second-line antiretroviral therapy in Sub-Saharan Africa: it is time to mind the gaps. AIDS Res Hum Retroviruses. 2017;33:1181-4.

7. World Health Organization, Hampton SG. Updated recommendations on first-line and second-line antiretroviral regimens and postexposure prophylaxis and recommendations on early infant diagnosis of HIV [Internet]; 2018. http://apps.who.int/iris/bitstream/ handle/10665/273632/WHO-CDS-HIV-18.18-eng.pdf?ua=1. Accessed 5 Oct 2018.

8. Ciaffi L, Koulla-Shiro S, Sawadogo A, le Moing V, EymardDuvernay S, Izard S, et al. Efficacy and safety of three second-line antiretroviral regimens in HIV-infected patients in Africa. AIDS Lond Engl. 2015;29:1473-81. 
9. Untangling The Web of Antiretroviral Price Reductions 18th edition [Internet]. Médecins Front. Access Campaign. https://msfac cess.org/untangling-web-antiretroviral-price-reductions-18th-editi on. Accessed 18 Sept 2018.

10. Dieleman JL, Haakenstad A, Micah A, Moses M, Abbafati C, Acharya P, et al. Spending on health and HIV/AIDS: domestic health spending and development assistance in 188 countries, 1995-2015. Lancet. 2018;391:1799-829.

11. Bendavid E, Wood R, Katzenstein DA, Bayoumi AM, Owens DK. Expanding antiretroviral options in resource-limited settingsa cost-effectiveness analysis. J Acquir Immune Defic Syndr. 1999;2009(52):106-13.

12. Simpson KN, Baran RW, Kirbach SE, Dietz B. Economics of switching to second-line antiretroviral therapy with lopinavir/ritonavir in Africa: estimates based on DART trial results and costs for Uganda and Kenya. Value Health J Int Soc Pharmacoeconomics Outcomes Res. 2011;14:1048-54.

13. Nichols BE, Sigaloff KC, Kityo C, Hamers RL, Baltussen R, Bertagnolio $\mathrm{S}$, et al. Increasing the use of second-line therapy is a cost-effective approach to prevent the spread of drug-resistant HIV: a mathematical modelling study. J Int AIDS Soc [Internet]; 2014. https://www.ncbi.nlm.nih.gov/pmc/articles/PMC42 60459/. Accessed 11 Sept 2018.

14. Schneider K, Nwizu C, Kaplan R, Anderson J, Wilson DP, Emery $\mathrm{S}$, et al. The potential cost and benefits of raltegravir in simplified second-line therapy among HIV infected patients in Nigeria and South Africa. PLoS ONE. 2013;8:e54435.

15. Petrou S, Gray A. Economic evaluation alongside randomised controlled trials: design, conduct, analysis, and reporting. BMJ. 2011;342:d1548.

16. Lara AM, Wakholi BN, Kasirye A, Munderi P, Watera C, Lalloo DG, et al. Utility assessment of HIV/AIDS-related health states in HIV-infected Ugandans. AIDS. 2008;22:S123.

17. Glick HA, Doshi JA, Sonnad SS, Polsky D. Economic evaluation in clinical trials. 2nd ed. Oxford: Oxford University Press; 2014.

18. World Health Organization. Global Price Reporting Mechanism [Internet]. WHO. http://apps.who.int/hiv/amds/price/hdd/. Accessed 21 June 2018.

19. The World Bank. World Development Indicators I DataBank: GDP deflator [Internet]. http://databank.worldbank.org/data/ reports.aspx ? source $=2 \&$ serie $s=N Y$.GDP.DEFL.ZS\&count ry $=$ BFA\&country $=$ CMR \& country $=$ SEN. Accessed 18 Sept 2018.

20. The World Bank. World Development Indicators | DataBank: Official exchange rate (LCU per US\$, period average) [Internet]. http://databank.worldbank.org/data/reports.aspx? source=2\&serie $\mathrm{s}=$ PA.NUS.FCRF \& count $\mathrm{ry}=\mathrm{BFA} \&$ count $\mathrm{r} y=\mathrm{CMR} \& \mathrm{count}$ ry=SEN. Accessed 18 Sept 2018.

21. Marshall G, Guo W, Jones RH. MARKOV: a computer program for multi-state Markov models with covariables. Comput Methods Programs Biomed. 1995;47:147-56.

22. Jackson C. Multi-state models for panel data: the msm package for R. https://www.jstatsoft.org/article/view/v038i08. Accessed 11 Sept 2018.

23. Simpson KN, Strassburger A, Jones WJ, Dietz B, Rajagopalan R. Comparison of Markov model and discrete-event simulation techniques for HIV. PharmacoEconomics. 2009;27:159-65.

24. Grover G, Gadpayle A, Swain P. A multistate Markov model based on CD4 cell count for HIV/AIDS patients on antiretroviral therapy (ART). Int J Stat Med Res [Internet]; 2013. http://www.lifescienc eglobal.com/home/cart?view $=$ product\&id=565. Accessed 11 Sept 2018.

25. Gray AM, Clarke PM, Wolstenholme JL, Wordsworth S. Applied methods of cost-effectiveness analysis in healthcare. Oxford: Oxford University Press; 2011.
26. Sachs J, WHO, editors. Macroeconomics and health: investing in health for economic development ; report of the Commission on Macroeconomics and Health. Geneva: World Health Organization; 2001.

27. The World Bank. World Development Indicators I DataBank: GDP per capita (constant 2010 US\$) [Internet]. http://databank.world bank.org/data/reports. aspx ?source $=2 \&$ series $=$ NY.GDP.PCAP. $\mathrm{CD} \&$ country $=\mathrm{CMR} \&$ country $=\mathrm{BFA} \& \&$ country $=\mathrm{SEN}$. Accessed 11 Sept 2018.

28. Marseille E, Larson B, Kazi DS, Kahn JG, Rosen S. Thresholds for the cost-effectiveness of interventions: alternative approaches. Bull World Health Organ. 2015;93:118-24.

29. Fenwick E, O'Brien BJ, Briggs A. Cost-effectiveness acceptability curves- facts, fallacies and frequently asked questions. Health Econ. 2004;13:405-15.

30. Médecins Sans Frontières. Stopping senseless deaths [Internet]. Médecins Front. Access Campaign. https://msfaccess.org/stopp ing-senseless-deaths. Accessed 27 Mar 2019.

31. Tengs TO, Lin TH. A meta-analysis of utility estimates for HIV/AIDS. Med Decis Making Int J Soc Med Decis Making. 2002;22:475-81.

32. Simpson KN, Jones WJ, Rajagopalan R, Dietz B. Cost effectiveness of lopinavir/ritonavir tablets compared with atazanavir plus ritonavir in antiretroviral-experienced patients in the UK, France, Italy and Spain. Clin Drug Investig. 2007;27:807-17.

33. Simpson KN, Pei PP, Möller J, Baran RW, Dietz B, Woodward $\mathrm{W}$, et al. Lopinavir/ritonavir versus darunavir plus ritonavir for HIV infection: a cost-effectiveness analysis for the United States. PharmacoEconomics. 2013;31:427-44

34. Foglia E, Bonfanti P, Rizzardini G, Bonizzoni E, Restelli U, Ricci E, et al. Cost-utility analysis of lopinavir/ritonavir versus atazanavir + ritonavir administered as first-line therapy for the treatment of HIV infection in Italy: from randomised trial to real world. PLoS ONE. 2013;8:e57777.

35. Long L, Fox M, Sanne I, Rosen S. The high cost of second-line antiretroviral therapy for HIV/AIDS in South Africa. AIDS Lond Engl. 2010;24:915-9.

36. Aboud M, Kaplan R, Lombaard J, Zhang F, Hidalgo J, Mamedova E, et al. Superior efficacy of dolutegravir (DTG) plus 2 nucleoside reverse transcriptase inhibitors (NRTIs) compared with lopinavir/ritonavir (LPV/RTV) plus 2 NRTIs in second-line treatment: interim data from the DAWNING study [Internet]; 2017. http:// programme.ias2017.org/Abstract/Abstract/5613. Accessed 10 Oct 2018.

37. Dorward J, Lessells R, Drain PK, Naidoo K, de Oliveira T, Pillay $\mathrm{Y}$, et al. Dolutegravir for first-line antiretroviral therapy in low-income and middle-income countries: uncertainties and opportunities for implementation and research. Lancet HIV. 2018;5:e400-4.

38. Vitoria M, Hill A, Ford N, Doherty M, Clayden P, Venter F, et al. The transition to dolutegravir and other new antiretrovirals in lowincome and middle-income countries: what are the issues? AIDS Lond Engl. 2018;32:1551-61.

39. World Health Organization. WHO statement on Dolutegravir [Internet]; 2018. http://www.who.int/medicines/publications/ drugalerts/Statement_on_DTG_18May_2018final.pdf?ua=1. Accessed 10 Oct 2018.

40. Phillips AN, Venter F, Havlir D, Pozniak A, Kuritzkes D, Wensing A, et al. Risks and benefits of dolutegravir-based antiretroviral drug regimens in sub-Saharan Africa: a modelling study. Lancet HIV. 2019;6:e116-27.

41. UNAIDS. New high-quality antiretroviral therapy to be launched in South Africa, Kenya and over 90 low-and middle-income countries at reduced price [Internet]. http://www.unaids.org/en/resou rces/presscentre/pressreleaseandstatementarchive/2017/septe mber/20170921_TLD. Accessed 10 Oct 2018. 


\section{Affiliations}

\section{S. Boyer ${ }^{1} \cdot$ M. L. Nishimwe ${ }^{1}$ (D) - L. Sagaon-Teyssier ${ }^{1,2} \cdot$ L. March $^{3} \cdot$ S. Koulla-Shiro ${ }^{4} \cdot$ M.-Q. Bousmah ${ }^{1,2} \cdot$ R. Toby $^{5}$.}

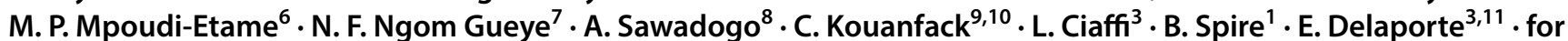
the 2-Lady Group

1 Aix Marseille Univ, INSERM, SESSTIM, IRD, Sciences Economiques et Sociales de la Santé et Traitement de l'Information Médicale, Marseille, France

2 ORS PACA, Observatoire régional de la santé Provence-Alpes-Côte d'Azur, Marseille, France

3 UMI 233, Institut de Recherche pour le Développement (IRD), INSERM U1175, University of Montpellier, Montpellier, France

4 Infectious Diseases Department, Yaoundé Central Hospital, Yaoundé, Cameroon

5 Day Care Unit, Central Hospital, Yaoundé, Cameroon
6 Epidemiology and Infectious Diseases Service, Region 1 Military Hospital, Yaoundé, Cameroon

7 Ambulatory Care Unit, Fann Hospital, Dakar, Senegal

8 Day Care Unit, University Hospital Souro Sanou, Bobo-Dioulasso, Burkina Faso

9 Yaoundé Central Hospital, Yaoundé, Cameroon

10 Faculty of Medicine and Pharmacology Sciences, Dschang University, Dschang, Cameroon

11 Department of Infectious Diseases, University Hospital, Montpellier, France 